\title{
Identification of (1E, 3E)-1, 3-bis [(2-hydroxy- 1-naphthyl) methylene] Urea as Mutated MAP Kinase P38 Inhibitor through Reverse Pharmacophore Mapping Approach: Green Synthesis, Characterisation and in silico Docking analysis
}

\author{
Devika Bhai Rajamma1, Girija Chamarahalli Ramakrishna lyer ${ }^{2,3^{*}}$, Inamul Hasan Madar, \\ Prashantha Karunakar ${ }^{6}$ \\ ${ }^{1}$ Research and Development Centre, Bharathiar University, Coimbatore, Tamil Nadu 641046, INDIA. \\ ${ }^{2}$ Department of Chemistry, SSMRV Degree College, Jayanagar $4^{\text {th }}$ T Block, Bangalore, Karnataka 560041, INDIA. \\ ${ }^{3}$ Department of Chemistry, Government Science College, Nrupatunga Road, Bangalore, Karnataka 560001, INDIA. \\ ${ }^{4}$ Department of Biotechnology and Genetic Engineering, Bharathidasan University, Tiruchirappalli, 620024, Tamil Nadu, INDIA. \\ ${ }^{5}$ Department of Biochemistry, Islamiah College, Vaniyambadi, 635751, Vellore, Tamil Nadu, INDIA. \\ ${ }^{6}$ Department of Biotechnology, PES University, Bangalore, Karnataka 560085, INDIA.
}

\begin{abstract}
Introduction: Investigations on Schiff bases are one of the current pharmaceutical research trends due to their broad-spectrum biological activities and unique structural features such as intramolecular hydrogen bond formation, unsaturated $\mathrm{C}-\mathrm{N}$ bond, the high mobility of hydrogen-bonded proton and pseudo aromatic ring formation. Aim: Current work is an attempt to discover the therapeutic potential of such structurally related Schiff bases compounds1-[(E)-[6-[(E)-(2-hydroxy-1-naphthyl) methyleneamino]2-pyridyl] iminomethyl] naphthalen-2-ol; P(a), (E)-1-(2-methoxy-1-naphthyl)-N-[6[(E)- (2-methoxy-1 - naphthyl) methyleneamino]-2-pyridyl] methanimine; $P(b)$, (E)-1(1-naphthyl)- N-[6-[(E)-1-naphthylmethyleneamino]-2-pyridyl] methanimine; $\mathrm{P}(\mathrm{c})$ and (1E,3E)-1,3-bis [(2-hydroxy-1-naphthyl)methylene]urea; P2(a). Materials and Methods: Reverse pharmacophore approach was used to identify the Mutated MAP Kinase P38 as the potent target for these selected compounds. The molecular docking studies were performed by using the glide module of Schrödinger Software suite and the Molecular Dynamics simulations were performed by using GROMACS 5.1 with OPLS force field. The in silico ADMET studies for all the compounds were performed using the online server SwissADME. The interesting results obtained from docking, dynamic simulation and ADMET properties of $\mathrm{P}(\mathrm{a}), \mathrm{P}(\mathrm{b}), \mathrm{P}(\mathrm{c})$ and $\mathrm{P} 2(\mathrm{a})$ led to the synthesis and characterisation of these compounds. Results: The docking and simulation studies showed the Schiff base P2(a) has the highest binding affinity. The ADMET profile inclusive of oral-bioavailability and physicochemical properties shown by this $\mathrm{P} 2$ (a) proves that it is the most pertinent lead molecule for a novel drug design. Conclusion: Hence, this work identifies the potential drug-like molecule (1E, 3E)-1,3-bis[(2-hydroxy-1-naphthyl) methylene] urea; P2(a) as Mutated MAP Kinase P38 inhibitor and provides the scope of advance in vivo studies to further explore the therapeutic potential of such compounds.
\end{abstract}

Key words: Schiff bases, Reverse PharmMapper, Molecular docking, Kinase inhibitor, Dynamics simulation, ADMET Studies.

\section{INTRODUCTION}

Schiff bases have received considerable attention in the current medicinal and pharmaceutical chemistry research areas due to their broad-spectrum biological activities like antimicrobial, ${ }^{1,2}$ anticancer ${ }^{3,4}$ analgesic ${ }^{5-8}$ anti-inflammatory ${ }^{5,7,9}$ antioxidant, ${ }^{10}$ anti-
Submission Date: 21-06-2018; Revision Date: 31-10-2018; Accepted Date: 18-01-2019

DOI: 10.5530/ijper.53.2.36 Correspondence: Dr. Girija Chamarahalli Ramakrishna lyer, Department of Chemistry, SSMRV Degree College, Jayanagar 4th T Block, Bangalore,

Karnataka 560041, INDIA. Phone: +919886419952 E-mail: girija.shivakumar@ rediffmail.com

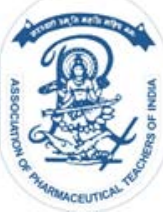

www.ijper.org 
tubercular activities. ${ }^{11}$ Schiff base molecules containing 2 , 6 diamino pyridine and naphthalene rings are reported as exhibiting excellent biological activities like antibacterial activities, antifungal properties, anticancer activities and their metal coordination behaviors have been reviewed and reported. ${ }^{12-16}$ Therefore, as a continuation of our investigations in biological activities of Schiff bases derived from naphthaldehyde; four structurally related Schiff bases 1-[(E)- [6-[(E)- (2-hydroxy-1-naphthyl) methyle neamino]-2-pyridyl] iminomethyl] naphthalen-2-ol; $\mathrm{P}(\mathrm{a})$, (E)-1-(2-methoxy-1-naphthyl)-N-[6-[(E)-(2-methoxy1-naphthyl)methyleneamino]-2-pyridyl]methanemine; $\mathrm{P}(\mathrm{b}), \quad$ (E)-1-(1-naphthyl)-N-[6-[(E)-1-naphthylmethyleneamino]-2-pyridyl] methanimine; $\mathrm{P}(\mathrm{c})$ and $(1 \mathrm{E}, 3 \mathrm{E})$ 1,3-bis[(2-hydroxy-1-naphthyl)methylene]urea; P2(a) ${ }^{17}$ were chosen (Figure 1) for in silico studies. The reverse PharmMapper method which is one of the most efficient target fishing strategies was applied for the initial screening.

\section{MATERIAL AND METHODS Pharm Mapper analysis}

Pharm Mapper is a web-based tool ${ }^{18}$ for potential drug target prediction against any given small molecules using a 'reverse' pharmacophore mapping method. This is a highly efficient mapping technique which has the high-throughput ability and identifies the potential target candidates from the database within a very short time. Pharm Mapper is a tool for identifying targets for a novel synthetic compound, a newly isolated natural product, a compound with known biological activity or an existing drug whose mechanism of action is unknown. ${ }^{19}$ Pharm Mapper screening was used to identify the potential target for the Schiff base $\mathrm{P}(\mathrm{c})$.

\section{Molecular docking}

The docking studies for Schiff base molecules were carried out by Glide program of Schrödinger Software suite. ${ }^{20}$ Schrödinger is commercial software that facilitates the finding of interactions by docking of a molecule at the active site of the target protein. The reverse docking server Pharm Mapper showed a large positive Z'-score of 2.916 with PDB id: 2GTN protein. ${ }^{21}$ Hence, this protein was selected as the target to perform docking studies on all the Schiff base molecules. The active site in the target protein was determined by analyzing the binding pattern of (2-(2, 6-difluorophenoxy)-n(2-fluorophenyl) - 9-isopropyl-9h-purin-8-amine) [LIE] which is co-crystallized and available in the $2 \mathrm{GTN}$ was used as control. The residues Gly110, Met109, Thr106, Ala51, Leu75, Leu86, Asp112, Val30, Phe169, Asn115,
Val38, Asp168 and Gly71 were observed as the interacting residues and assisted in the binding of a ligand with the protein as shown in Figure 2. Prior to docking, the target protein was prepared by protein preparation wizard to add hydrogen, correct structural errors, add missing atoms and remove extra water and other hetero molecules attached to the protein. SMILE formats of all synthetic Schiff base molecules were taken as input to the Ligprep module to prepare ligand molecules for docking studies.

The grid was created on the target protein with all residues of the active site with van der Waals $(\mathrm{VdW})$ radii scaling factor of 1 , partial cutoff charge 0.25 and grid center at $-2.250954,-0.742516$ and 19.284213 coordinates. Total grid point at the inner box and outer boxes were $10 \times 10 \times 10$ and $27 \times 27 \times 27$ respectively. The docking was performed on the receptor grid using

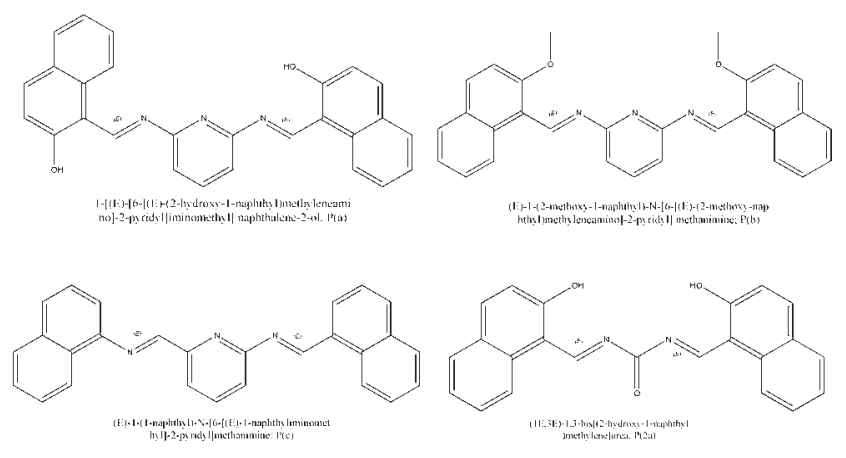

Figure 1: Structure of $P(a), P(b), P(c)$ and $P 2(a)$.

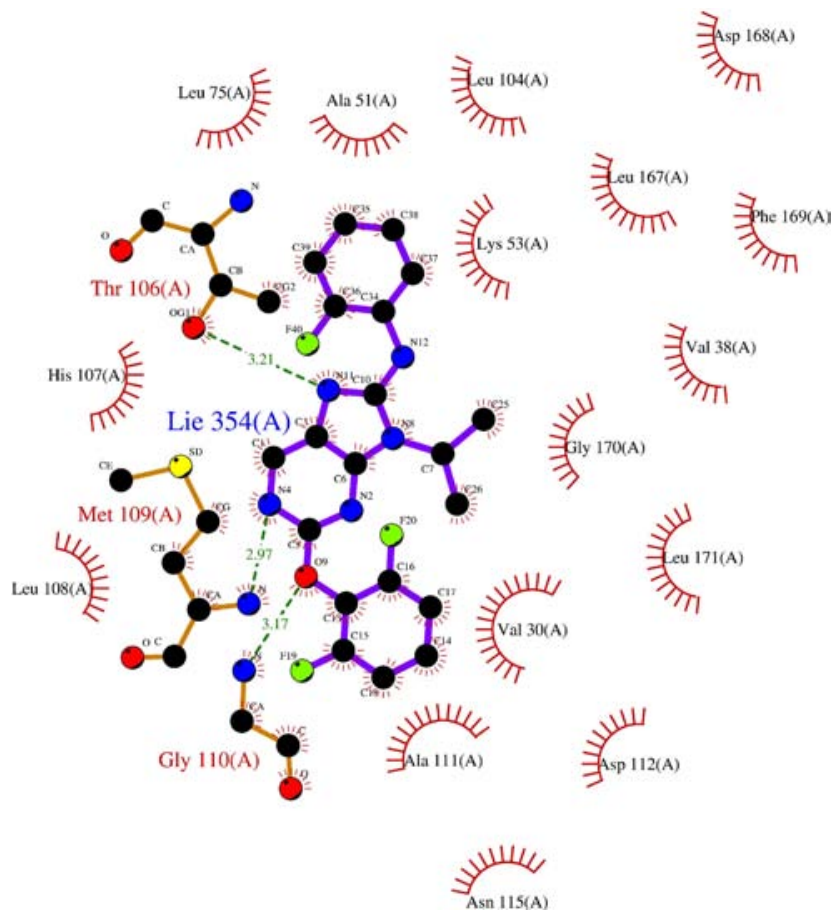

Figure 2: Active site residues of 2GTN from PDB Sum. 
VdW scaling factor 0.80 and 0.15 charge cutoff. The standard precision was used on flexible ligand sampling with sample nitrogen inversion and sample ring conformations. OPLS (Optimized Potential for Liquid Simulation) methods were used for energy calculation of docked molecular conformations.

\section{Molecular dynamics simulation}

The Molecular Dynamics simulations for each proteinligand system were performed at $300 \mathrm{~K}$ using GROMACS $5.1^{22}$ with OPLS force field. The initial topologies were generated using PRODRG server ${ }^{23}$ and tweaked using in-house tools after optimizing it with MOPAC. ${ }^{24}$ The topology parameters of MAP kinase P38 and the Schiff bases ligands were generated using GROMACS program and PRODRG server respectively to generate a protein-ligand complex system. A dodecahedron box of $1 \mathrm{~nm}$ was created around the complex periphery with periodic boundary condition using gmxeditconf. This box was filled with Tip4P water model to create real-life simulation of protein using gmx solvate. The system was neutralized by the addition of $\mathrm{Na}^{+}$and $\mathrm{Cl}^{-}$ ions using gmxgenion. The resultant system was subjected to 1000 steps of minimization to achieve a stable conformation of the complex and to remove the internal clashing of complex and water molecules. Using NVT, the system was systematically heated from 0 to $300 \mathrm{~K}$ with $100 \mathrm{ps}$ equilibration conditions and periodic boundary condition. The second equilibration was done on the resultant system of NVT with NPT conditions for $100 \mathrm{ps}$. The equilibration protein backbone atoms were restrained and side chain as well as ligand molecule were allowed to move freely. After equilibration, all the four systems were subjected to $20 \mathrm{~ns}$ of simulation at $300 \mathrm{~K}$ with Verlet cutoff scheme along with particlemesh Ewald method ${ }^{25}$ at $300 \mathrm{~K}$.

\section{Chemistry}

An efficient green protocol by using Microwave irradiation has been reported for the synthesis of the Schiff bases $\mathrm{P}(\mathrm{a}), \mathrm{P}(\mathrm{b}), \mathrm{P}(\mathrm{c})$ and $\mathrm{P} 2(\mathrm{a}){ }^{26}$ This method provided a better Yield and faster reaction without using hazardous and toxic dehydrating agents like $\mathrm{H}_{2} \mathrm{SO}_{4}, \mathrm{TiCl}_{4}$ and $\mathrm{MgSO}_{4}$-PPTS as compared to the classical method. ${ }^{27}$ Moreover, the quantity of solvent used in this reaction is considerably less compared to the conventional synthesis.

All the reagents required for the reaction were sourced from Aldrich Chemicals and were chemically pure. The solvents were freshly distilled before use. Microwave synthesis was carried out in a Technika domestic microwave oven with model number WD904 at power 300W.
LC-MS analysis was performed using WATERS LCMS Model (SQD-2 with H Class UPLC) at Azyme Biosciences, Bangalore, India. ESI HRMS was done using Agilent 6520 Q-TOF at Central Drug Research Institute, Lucknow, India. Infra-red spectra of complexes were recorded in $\mathrm{KBr}$ pellets with a JASCO FTIR in the range of $4000-400 \mathrm{~cm}^{-1} .{ }^{1} \mathrm{H}-\mathrm{NMR}(400 \mathrm{MHz})$ were recorded with JEOL 400-MHZ NMR Spectrophotometer (with Multiple Probe Facility) using TMS as the internal reference.

Synthesis of 1-[(E)-[6-(E) -(2-hydroxy-1-naphthyl) methyleneamino]-2 pyridyl] iminomethyl] naphthalene 2-ol, $\mathbf{P ( a )}$ : A mixture of 2,6 Diamino pyridine $(0.500 \mathrm{~g}, 0.458 \mathrm{mmol})$ and 2-Hydroxy-1- naphthaldehyde $(1.5 \mathrm{~g}, 0.916)$ in $2 \mathrm{ml}$ of ethanol was irradiated in a microwave oven for $6 \mathrm{~min}$. The reaction mixture was then dissolved in $10 \mathrm{ml}$ of hot ethanol and stirred for $5 \mathrm{~h}$ and cooled to get crystalline reddish-brown solid as the product...

Synthesis of (E)-1-(2-methoxy-1-naphthyl)-N-[6[(E)-(2-methoxy-1-naphthyl) methylene amino]2-pyridyl] methanimine $\mathbf{P}$ (b): The reaction was carried by using the same protocol used for the synthesis of $\mathrm{P}(\mathrm{a})$. A mixture of 2,6 Diamino pyridine $(0.500 \mathrm{~g}$, $0.458 \mathrm{mmol})$ and 2-Methoxy-1- naphthaldehyde (1.7g, $0.916)$ in $2 \mathrm{ml}$ of ethanol was irradiated in a microwave oven for $6 \mathrm{~min}$. The reaction mixture was then dissolved in $10 \mathrm{ml}$ of hot ethanol, stirred for $7 \mathrm{~h}$ and cooled to get the product as crystalline bright yellow colored powder. Synthesis of (E)-1-(1-naphthyl)-N-[6-[(E)-1naphthylmethyleneamino]-2-pyridyl] methanimine, $\mathbf{P}(\mathbf{c})$ : The reaction was carried by using the same protocol used for the synthesis of $\mathrm{P}(\mathrm{a})$. 2,6 Diamino pyridine $(0.500 \mathrm{~g}, 0.458 \mathrm{mmol})$ and 1 -naphthaldehyde $(1.4 \mathrm{~g}, 0.916)$ was mixed with $2 \mathrm{ml}$ of ethanol and the mixture was irradiated in a microwave oven for $4 \mathrm{~min}$. The resultant mixture was then dissolved in $10 \mathrm{ml}$ of hot ethanol, stirred for $7 \mathrm{~h}$ and cooled to get the product as bright yellow colored powder.

Synthesis of (1E, 3E)-1,3-bis[(2-hydroxy-1-naphthyl) methylene]urea, P2(a): The same protocol which was used for the synthesis of $\mathrm{P}(\mathrm{a})$ is used here. Urea $(0.200 \mathrm{~g}, 3.3 \mathrm{mmol})$ and 1-naphthaldehyde (1.1g, $6.6 \mathrm{mmol}$ ) was mixed with $2 \mathrm{ml}$ of ethanol and the mixture was irradiated in a microwave oven for $8 \mathrm{~min}$. The resultant mixture was then dissolved in $8 \mathrm{ml}$ of hot ethanol, stirred for $7 \mathrm{~h}$ and cooled to get bright yellow colored fine powder as product.

\section{Spectral characterisation of the Schiff bases}

1 - [ (E) - [ 6 - (E) - ( 2 - hyd roxy - 1 - n a ph thy 1$)$ methyleneamino]-2-pyridyl] iminomethyl] naph- 
thalene 2-ol, $\mathbf{P}$ (a): Yield: $85 \%$. M.p: $280-285^{\circ} \mathrm{C}$. IR $\left(\mathrm{KBR}, v, \mathrm{~cm}^{-1}\right)$ : $1616(\mathrm{C}=\mathrm{N}), 1347$ (phenolic C-O); 830 (CH). ${ }^{1} \mathrm{H}$ NMR $\left(400 \mathrm{MHz}, \mathrm{CDCl}_{3} \delta, \mathrm{ppm}\right): 15.17(\mathrm{~d}, 2 \mathrm{H}$, $\mathrm{OH}), 10.03(\mathrm{~d}, 2 \mathrm{H}, \mathrm{HC}=\mathrm{N}), 8.170(\mathrm{~d}, 2 \mathrm{H}, \mathrm{Ar}-\mathrm{H}), 7.82$. ( d, $2 \mathrm{H}, \mathrm{Ar}-\mathrm{H}), 7.79-7.76(\mathrm{~m}, 1 \mathrm{H}, \mathrm{Ar}-\mathrm{H}), 7.67-7,65(\mathrm{~m}$, $2 \mathrm{H}, \mathrm{Ar}-\mathrm{H}), 7.58-7.54(\mathrm{~m}, 2 \mathrm{H}, \mathrm{Ar}-\mathrm{H}), 7.37-7.36(\mathrm{~m}, 2 \mathrm{H}$, Ar-H), 7.03 (d, 2H, Ar-H), 6.94(d, 2H, Ar-H). EI-MS: $\mathrm{m} / \mathrm{z}[\mathrm{M}+\mathrm{H}]+: 418.1$

(E)-1-(2-methoxy-1-naphthyl)-N-[6-[(E)-(2methox-1-naphthyl) methylene amino]-2-pyridyl] methanimine $\mathbf{P}(\mathbf{b})$ : Yield: $80 \%$. M.p: $260-265^{\circ} \mathrm{C}$. IR $(\mathrm{KBR}, \nu, \mathrm{cm}-1): 1592(\mathrm{C}=\mathrm{N}), 1247$ (methoxy C-O), $807(\mathrm{CH}) .{ }^{1} \mathrm{H}$ NMR $(400 \mathrm{MHz}, \mathrm{CDCl} 3, \delta, \mathrm{ppm}): 10.9$ $(\mathrm{s}, 2 \mathrm{H}, \mathrm{HC}=\mathrm{N}) ; 9.27(\mathrm{~d}, 2 \mathrm{H}, \mathrm{Ar}-\mathrm{H}), 8.06(\mathrm{~d}, 2 \mathrm{H}, \mathrm{Ar}-\mathrm{H})$, 7.98-7.95 (m, 2H, Ar-H), 7.91 (d, 2H, Ar-H), 7.78-7.76 (m, 2H, Ar- $\mathrm{H}), 7.67-7.65$ (m, 2H, Ar- $\mathrm{H}), 7.44-7.40$ (m, 1H, Ar-H), 7.30 (d, 2H, Ar-H), 4.059 (s, 6H, -OCH3). EI-MS: $\mathrm{m} / \mathrm{z}[\mathrm{M}+\mathrm{H}]+: 447.2$

( E ) - 1 - ( 1 - n a p h t h y 1$)-\mathrm{N}-[6-[$ ( E ) - 1 naphthylmethyleneamino]-2-pyridyl] methanimine, P(c): Yield:70\%. M.p: $215-220^{\circ} \mathrm{C}$. IR (KBR, v, $\left.\mathrm{cm}^{-1}\right):(\mathrm{C}=\mathrm{N})$ 1578, $(\mathrm{CH})$ 813. ${ }^{1} \mathrm{H}$ NMR $(400 \mathrm{MHz}$, $\left.\mathrm{CDCl}_{3} \delta, \mathrm{ppm}\right): 10.172(\mathrm{~s}, 2 \mathrm{H}, \mathrm{HC}=\mathrm{N}), 9.30(\mathrm{~d}, 2 \mathrm{H}),$, (d, 2H, Ar-H),8.6(d, 2H, Ar-H),7.9(d, 2H, Ar-H),7.957.93(m, 2H, Ar-H), 7.78-7.75(m, 4H, Ar-H), 7.55-5.53(m, $2 \mathrm{H}, \mathrm{Ar}-\mathrm{H}), 7.31(\mathrm{~d}, 2 \mathrm{H}, \mathrm{Ar}-\mathrm{H})$. EI-MS: $\mathrm{m} / \mathrm{z}[\mathrm{M}-\mathrm{H}]: 384.4$ (1E, 3E)-1, 3-bis [(2-hydroxy-1-naphthyl) methylene] urea; P2(a): Yield: $98.7 \%$. M.P: $187^{\circ} \mathrm{C}$. IR (KBR, $\left.v, \mathrm{~cm}^{-1}\right): 1597(\mathrm{C}=\mathrm{N}), 3072(\mathrm{OH}$, broad $), 750(\mathrm{C}-\mathrm{H}) .{ }^{1} \mathrm{H}$ NMR (400 MHz, DMSO-D6, $\delta$ ppm): 13.2 (s, 2H, OH) 9.01 (s, 2H, HC=N), 8.25-8.22 (m, 2H, Ar-H), 7.79 (d, 2H, Ar-H), 7.62 (d, 2H, Ar-H), 7.29-7.27 (m, 2H, Ar-H), 7.16-7.13 (m, 2H, Ar-H), 6.59 (d, 2H, Ar-H). EI-MS: $\mathrm{m} / \mathrm{z}[\mathrm{M}+\mathrm{H}]+369.3$

\section{In-silico physicochemical and Absorption, Distribution, Metabolism, Excretion and Toxicity properties.}

The in silico ADMET study for the four compounds were performed using the online server SwissADME which reads the mol file and converts it to Single Line Input Line Entry System (SMILES) to predict the Physicochemical Properties, Lipophilicity, Water Solubility, Pharmacokinetics and Druglikeness. ${ }^{28}$

\section{RESULTS AND DISCUSSION}

\section{Pharm Mapper analysis}

Potential protein was identified using reverse pharmacology mapping via Pharm Mapper the top potential receptors based on Z' score and their association with cancer pathway were selected. The reverse docking server Pharm Mapper showed a large positive Z'-score of 2.916 with 2GTN protein. In vitro studies of the compounds containing tridentate Schiff base bearing a simple 2',4'-dihydroxyacetophenone functionality and ethylenediamine as the bridging ligand with $\mathrm{RCHO}$ moiety have demonstrated antiproliferative activity. ${ }^{29}$ Thus, our results very well correlate with the experimental evidence and found that Mitogenactivated Kinase protein (Protein ID: 2GTN) exhibited excellent interactions with the base compound $\mathrm{P}(\mathrm{c})$.

\section{Molecular docking}

Ligand-receptor interactions of a particular class of compounds can be improved by making careful changes in the functional groups of the core structure of these molecules. The Schiff base molecules of interest possessed functional groups which can play significant roles in hydrogen bonding, hydrophic and pi-pi interactions. The hydroxyl groups on the naphthalene residue were expected to act as hydrogen bond donors, whereas the methoxy groups were expected to function as hydrogen bond acceptors. Hydrophobic interactions were also predicted due to the presence of naphthalene rings.

A close analysis of docking figures suggests that the molecules are appropriately embedded into the protein active site where one of the naphthalene rings in all the Schiff bases (Figure 3) seemed to be out from the active site and these are the solvent accessible surface of the molecules. This may be attributed to the unique conformation of these molecules provided by the bulkier naphthalene rigs. In order to minimize the steric hindrance, these molecules are expected to undergo $\mathrm{C}-\mathrm{C}$ bond rotation and adopt a conformation where one of the naphthalene rings is perpendicular to the plane of other parts of the molecules. Molecules $\mathrm{P} 2(\mathrm{a})$ and $\mathrm{P}(\mathrm{a})$ provided a hydrogen bond donor site as expected due to the presence of the ortho hydroxyl group. However, P2(a) exhibited better docking scores due to an additional oxygen atom from the urea moiety. All the four Schiff bases being Salen type compounds exhibited varying docking proficiency. The increased potency of $\mathrm{P} 2(\mathrm{a})$ and $\mathrm{P}(\mathrm{a})$ can be due to the involvement of hydroxyl group present in their structures. Previous reports on the role of hydroxy groups in protein docking are in agreement with our findings. Ling Qiu et al. have explained the importance of hydroxyl group of a well-known intravenous anesthetic. ${ }^{30}$

All residues which were found interacting with the co-crystallized ligand LIE were also found to be involved at the same binding site of $\mathrm{P} 2(\mathrm{a}), \mathrm{P}(\mathrm{a}), \mathrm{P}(\mathrm{b})$ and $\mathrm{P}(\mathrm{c})$ molecules. Table 1 shows the various parameters 

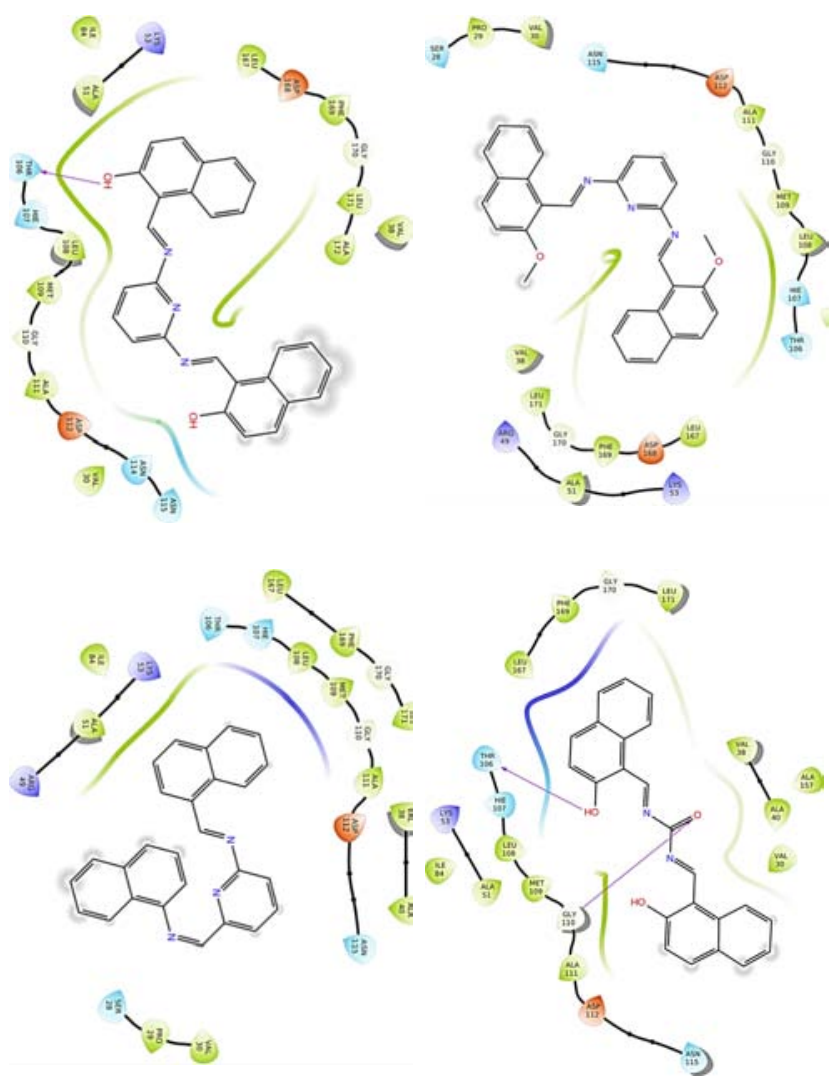

Figure 3: Docking interaction of $P(a): 1, P(b): 2 . P(c): 3$ and P2(a):4

that were analyzed while comparing the docking studies. As per parameters of docking, it was found that P2(a) is the best docked molecule with docking score -7.84 and glide score -7.84 among all other Schiff base molecules. It is important to note that the interactions of Schiff bases with the amino acid residues were not exclusively hydrophobic; as some of the residues (Arg 49, His 107) in the vicinity of the ligands were polar in nature. On the other hand, Schiff base molecules $\mathrm{P}(\mathrm{a})$ and P2(a) were able to form hydrogen bonds with Thr 106. P2(a) exhibited additional hydrogen bonding with Gly110 due to the $\mathrm{C}=\mathrm{O}$ functionality from urea which plays a considerable role in stabilizing of Schiff base - protein complex (Figure 3). The docking results were in agreement with the experimental results from PDB Sum of 2 GTN. ${ }^{23,31}$ The formation of a hydrogen bond is conserved in both the co-crystallized molecule LIE and ligands P2(a) and P(a) with Thr 106 (Figure 2 and 3).

\section{Molecular Dynamics Simulation}

The obtained docking results of Schiff base ProteinLigand complex allowed us to propose a general binding mode of the ligands and to determine residues involved in the ligand recognition. Although molecular docking offers reasonable binding structures for investigated

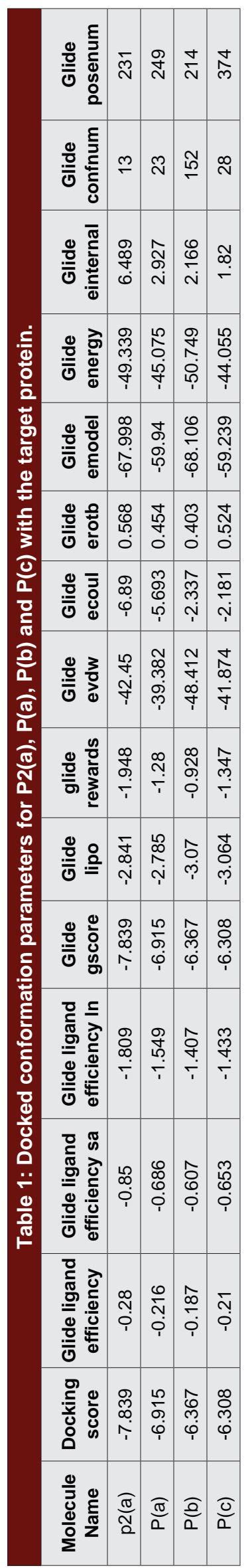


ligands, the MD simulation can account for further investigation of binding modes of ligands and also explains the effects of ligand binding on the conformation and stability of the protein. The Protein-Ligand complex with the least binding energy was obtained from the docking program and was subjected to molecular dynamics simulation. The $\mathrm{P}(\mathrm{a}), \mathrm{P}(\mathrm{b}), \mathrm{P}(\mathrm{c})$ and $\mathrm{P} 2(\mathrm{a})$ ligands bound to protein were simulated to check the stability of protein backbone.

The RMSD plot (Figure 4) shows the relative stability based on the motion of the protein backbone when bound with Schiff bases. P2(a), which shows the best binding mode among all the Schiff bases, also shows the lowest deviation from the $\mathrm{X}$-ray structure and tends to converge after 10 ns. Similarly, P(a) starts with a higher fluctuation and shows a slightly high fluctuation between $3.5 \mathrm{~ns}$ and $4.5 \mathrm{~ns}$ becomes more converged subsequently. After $8 \mathrm{~ns}$, it shows a very stable motion and may be a good candidate for further studies. P(c) and $\mathrm{P}(\mathrm{b})$ show a very high fluctuation in their backbone throughout. This may be due to steric clashes between the drug and the active site region residues.

Fluctuations in similar fashion can also be observed in the Root Mean Square Fluctuation (RMSF) plot (Figure 5) where the residues constituting the active site (between residues 35-105) show a relatively lower fluctuation in $\mathrm{P} 2(\mathrm{a})$ and $\mathrm{P}(\mathrm{a})$ than that of other complexes. Molecular dynamics results suggest that both the Schiff base complexes can interact with map kinase p38, without affecting the secondary structure. All the molecular docking and molecular dynamics results were well consistent with the experimental data. Structural information regarding binding mode and the effects of Schiff bases on the protein stability and structure were reported here. The results obtained from the docking, ADMET properties and molecular dynamic (MD) simulation studies of $\mathrm{P}(\mathrm{a}), \mathrm{P}(\mathrm{b}), \mathrm{P}(\mathrm{c})$ and $\mathrm{P} 2(\mathrm{a})$ led to the synthesis and characterization of these molecules for further investigations.

\section{In-silico physicochemical and ADMET properties}

ADMET study provides the significant data for deciding a right preclinical drug candidate by screening them based on their absorption, distribution, metabolism, excretion and toxicity. The in-silico physicochemical and ADMET properties for all four synthetic Schiff base molecules are shown in Table 2. Although none of the Schiff bases are Violating Lipinski's rule; compound P2(a) is observed to have the most favorable physicochemical and ADMET properties such as number of rotatable bonds, $\mathrm{H}$-bond acceptors, $\mathrm{H}$-bond donors and $\log \mathrm{P}$ values with non-violation of all the rules including Lipinski, Ghose, Veber, Egan and Muegge violations rules.

\begin{tabular}{|c|c|c|c|c|c|}
\hline & Molecule & P2(a) & $P(a)$ & $P(b)$ & $P(c)$ \\
\hline \multirow{15}{*}{ 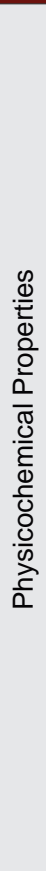 } & Canonical SMILES & $\begin{array}{l}\mathrm{O}=\mathrm{C}(/ \mathrm{N}=\mathrm{C} / \mathrm{c} 1 \mathrm{c}(\mathrm{O}) \\
\mathrm{ccc} 2 \mathrm{c} 1 \mathrm{ccc} 2) / \mathrm{N}=\mathrm{C} / \\
\mathrm{c} 1 \mathrm{c}(\mathrm{O}) \operatorname{ccc} 2 \mathrm{c} 1 \mathrm{cccc} 2\end{array}$ & $\begin{array}{c}\mathrm{Oc} 1 \mathrm{ccc} 2 \mathrm{c}(\mathrm{c} 1 / \mathrm{C}=\mathrm{N} / \\
\mathrm{c} 1 \operatorname{cccc}(\mathrm{n} 1) / \mathrm{N}=\mathrm{Cl} \\
\mathrm{c} 1 \mathrm{c}(\mathrm{O}) \operatorname{ccc} 3 \mathrm{c} 1 \mathrm{cccc} 3) \\
\operatorname{cccc} 2\end{array}$ & $\begin{array}{c}\mathrm{cOc} 1 \mathrm{ccc} 2 \mathrm{c}(\mathrm{c} 1 / \mathrm{C}=\mathrm{N} / \\
\mathrm{c} 1 \mathrm{cccc}(\mathrm{n} 1) / \mathrm{N}=\mathrm{C} / \\
\mathrm{c} 1 \mathrm{c}(\mathrm{OC}) \operatorname{ccc} 3 \mathrm{c} 1 \mathrm{cccc} 3) \\
\operatorname{cccc} 2\end{array}$ & $\begin{array}{c}\mathrm{c} 1 \mathrm{cc}(/ \mathrm{C}=\mathrm{N} / \\
\mathrm{c} 2 \mathrm{cccc} 3 \mathrm{c} 2 \mathrm{cccc} 3) \\
\mathrm{nc}(\mathrm{c} 1) / \mathrm{N}=\mathrm{C} / \\
\mathrm{c} 1 \mathrm{cccc} 2 \mathrm{c} 1 \mathrm{cccc} 2\end{array}$ \\
\hline & Formula & $\mathrm{C} 23 \mathrm{H} 16 \mathrm{~N} 2 \mathrm{O} 3$ & $\mathrm{C} 27 \mathrm{H} 19 \mathrm{~N} 3 \mathrm{O} 2$ & $\mathrm{C} 29 \mathrm{H} 23 \mathrm{~N} 3 \mathrm{O} 2$ & C27H19N3 \\
\hline & MW & 368.4 & 417.4 & 445.5 & 385.4 \\
\hline & Heavy atoms & 28 & 32 & 34 & 30 \\
\hline & Aromatic heavy atoms & 20 & 26 & 26 & 26 \\
\hline & Fraction Csp3 & 0 & 0 & 0.07 & 0 \\
\hline & Rotatable bonds & 4 & 4 & 6 & 4 \\
\hline & H-bond acceptors & 5 & 5 & 5 & 3 \\
\hline & $\mathrm{H}$-bond donors & 2 & 2 & 0 & 0 \\
\hline & Iso Electric Point & 2.8 & 3.4 & - & - \\
\hline & Refractivity & 109.2 & 132 & 141 & 127.3 \\
\hline & Polarizability & 43.2 & 50 & 53.9 & 49 \\
\hline & $\log P$ & 4.5 & 7 & 7.3 & 7.7 \\
\hline & Pka & $\begin{array}{c}\text { 7.8/8.4 (Two } \\
\text { Protonation Sites) }\end{array}$ & $\begin{array}{c}8.32 / 8.9 \text { (Two } \\
\text { Protonation Sites) }\end{array}$ & -1.6 & $0.4 /-1.2$ \\
\hline & MR & 112.5 & 130.6 & 139.6 & 126.6 \\
\hline
\end{tabular}




\begin{tabular}{|c|c|c|c|c|c|}
\hline & & Table & nt'd. & & \\
\hline & Molecule & P2(a) & $P(a)$ & $P(b)$ & $P(c)$ \\
\hline & TPSA & 82.2 & 78 & 56 & 37.6 \\
\hline & iLOGP & 3.6 & 3.6 & 3.8 & 4 \\
\hline & XLOGP3 & 4.9 & 5.9 & 6.5 & 6.6 \\
\hline 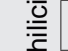 & WLOGP & 5 & 6.3 & 6.9 & 6.8 \\
\hline 믕 & MLOGP & 3.5 & 4.3 & 4.7 & 4.6 \\
\hline & Silicos-IT Log P & 5.2 & 6.3 & 7.4 & 7.3 \\
\hline & Consensus Log $\mathrm{P}$ & 4.5 & 5.3 & 5.8 & 5.9 \\
\hline & ESOL Log S & -5.5 & -6.5 & -6.9 & -6.7 \\
\hline & ESOL Solubility (mg/ml) & 1.11E-03 & 1.35E-04 & 5.55E-05 & 6.43E-05 \\
\hline & ESOL Solubility (mol/l) & 3.02E-06 & 3.24E-07 & 1.24E-07 & 1.67E-07 \\
\hline & ESOL Class & Moderately soluble & Poorly soluble & Poorly soluble & Poorly soluble \\
\hline$\geqq$ & Ali Log S & -6.44 & -7.32 & -7.54 & -7.21 \\
\hline$\frac{\overline{\overline{0}}}{2}$ & Ali Solubility $(\mathrm{mg} / \mathrm{ml})$ & 1.35E-04 & $1.98 \mathrm{E}-05$ & 1.30E-05 & 2.37E-05 \\
\hline$\overline{0}$ & Ali Solubility (mol/l) & 3.67E-07 & 4.75E-08 & 2.91E-08 & $6.16 \mathrm{E}-08$ \\
\hline 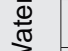 & Ali Class & Poorly soluble & Poorly soluble & Poorly soluble & Poorly soluble \\
\hline & Silicos-IT LogSw & -7.2 & -9.35 & -10.73 & -10.53 \\
\hline & Silicos-IT Solubility (mg/ml) & 2.34E-05 & $1.85 \mathrm{E}-07$ & 8.28E-09 & 1.14E-08 \\
\hline & Silicos-IT Solubility (mol/l) & $6.34 \mathrm{E}-08$ & $4.44 \mathrm{E}-10$ & $1.86 \mathrm{E}-11$ & $2.95 \mathrm{E}-11$ \\
\hline & Silicos-IT class & Poorly soluble & Poorly soluble & Insoluble & Insoluble \\
\hline & Gl absorption & High & High & Low & Low \\
\hline & BBB permeant & No & No & No & No \\
\hline$\tilde{y}$ & Pgp substrate & No & No & No & No \\
\hline$\stackrel{\bar{c}}{\frac{\bar{c}}{\bar{y}}}$ & CYP1A2 inhibitor & No & No & No & Yes \\
\hline 范 & CYP2C19 inhibitor & No & No & Yes & Yes \\
\hline है ฮు & CYP2C9 inhibitor & No & No & Yes & No \\
\hline $\bar{\alpha}$ & CYP2D6 inhibitor & No & No & No & No \\
\hline & CYP3A4 inhibitor & No & No & Yes & No \\
\hline & $\log K p(\mathrm{~cm} / \mathrm{s})$ & -5 & -4.6 & -4.3 & -3.9 \\
\hline & Lipinski violations & 0 & 1 & 1 & 1 \\
\hline$\oiiint$ & Ghose violations & 0 & 2 & 2 & 1 \\
\hline$\stackrel{\mathscr{Q}}{\mathscr{Q}}$ & Veber violations & 0 & 0 & 0 & 0 \\
\hline$\frac{\overline{\bar{T}}}{\mathrm{z}}$ & Egan violations & 0 & 1 & 1 & 1 \\
\hline ڤั & Muegge violations & 0 & 1 & 1 & 1 \\
\hline & Bioavailability Score & 0.5 & 0.5 & 0.5 & 0.5 \\
\hline$\stackrel{\mathscr{D}}{=}$ & PAINS alerts & 0 & 0 & 0 & 0 \\
\hline$\frac{\bar{d}}{0}$ & Brenk alerts & 1 & 1 & 1 & 1 \\
\hline$\overline{\bar{\alpha}}$ & Leadlikeness violations & 2 & 2 & 2 & 2 \\
\hline 点 & Synthetic Accessibility & 3.1 & 3.4 & 3.6 & 3.4 \\
\hline
\end{tabular}


RMSD

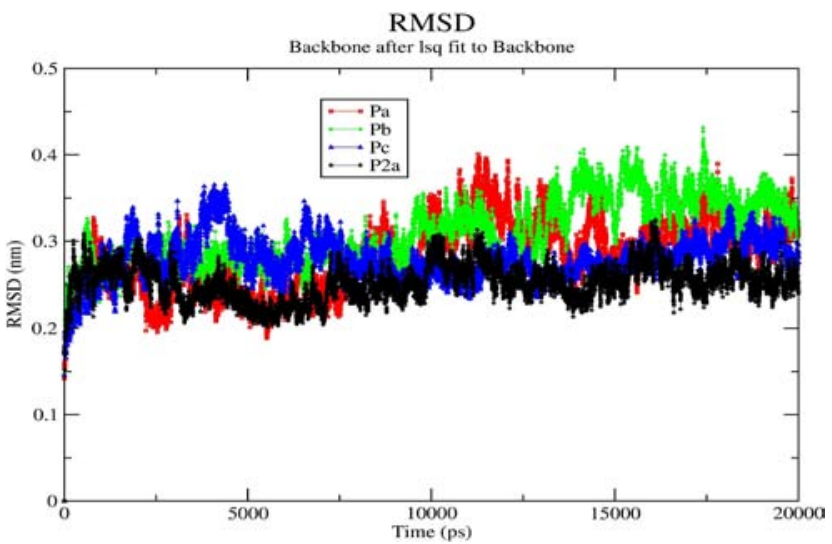

Figure 4: Time dependence of the Root Mean Square Deviation for the backbone atoms of protein during the simulation in the presence of Schiff base. $P(a)$ : Red, $P(b)$ : Green, $P(c)$ : Blue and P2(a): Black.

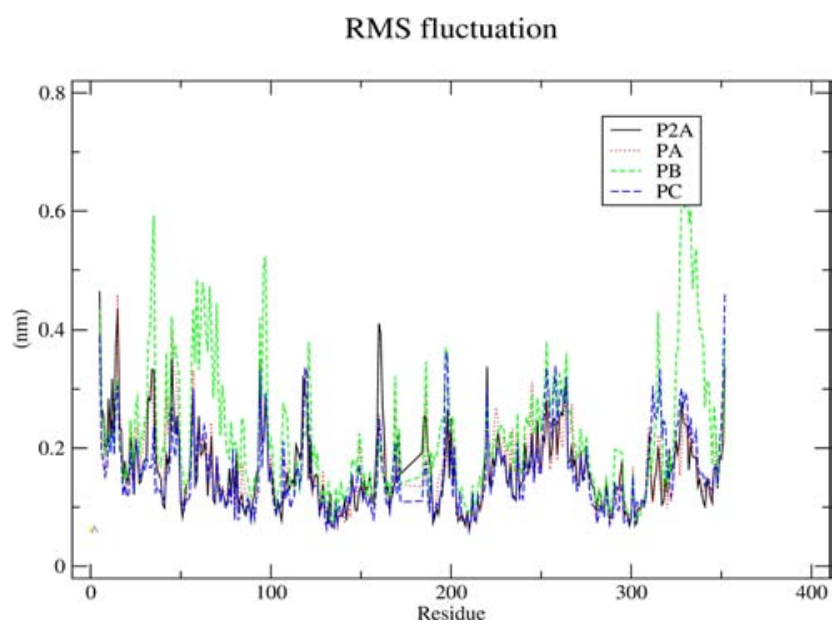

Figure 5: Root mean square fluctuation plot with 2GTN (P2(a) : P2A, P(a) : PA, P(b) : $P B$ and $P(c): P C)$.

\section{ABBREVIATIONS}

ADMET:Absorption, distribution, metabolism, excretion, toxicity; PDB id: Protein Data Bank identification code; LIE: 2-(2, 6-difluorophenoxy)-n-(2-fluorophenyl) 9-isopropyl-9h-purin-8-amine; SMILE: Simplified molecular-input line-entry system; VdW: Van der Waals; OPLS: Optimized Potential for Liquid Simulation; MOPAC: Molecular Orbital PACkage; LC-MS: Liquid chromatography-mass spectrometry; FTIR: Fourier-transform infrared spectroscopy; ${ }^{1} \mathbf{H}-\mathbf{N M R}$ : Proton nuclear magnetic resonance; TMS: Tetramethylsilane; h: Hour; M.p: Melting point; C-C: CarbonCarbon bond; RMSD: Root Mean Square Deviation; RSMF: Root Mean Square Fluctuation; MD: Molecular dynamic.

\section{REFERENCES}

1. Suzan MA, Wamidh TH, Mohammad MS, Mubarak MS, Murad AA. Synthesis, characterization antimicrobial activity of Schiff bases derived from benzaldehydes and 3, 3'-diaminodipropylamine. Arab J Chem. 2015;8(6):850-7.

2. Hong-Jia Z, Xuan Q, Kai L, Di-Di Z, Xiao-Ming W, Hai-Liang Z. Synthesis, antibacterial activities and molecular docking studies of Schiff bases derived from N-(2/4-benzaldehyde-amino) phenyl-N'-phenyl-thiourea. Bioorg Med Chem. 2011;19(18):5708-15.

3. Miri R, Razzaghi-asI N, Mohammadi MK. QM study and conformational analysis of an isatin Schiff base as a potential cytotoxic agent. J Mol Model. 2013;19(2):727-35.

4. Ali SMM, Abul KAM, Jesmin M. In vivo anticancer activity of Vanillin semicarbazone. Asian Pac J Trop Biomed. 2012;2(6):438-42.

5. Sondhi SM, Singh N, Kumar A, Lozach O, Meijer L. Synthesis, antiinflammatory, analgesic and kinase (CDK-1, CDK-5 and GSK-3) inhibition activity evaluation of benzimidazole/ benzoxazole derivatives and some Schiff's bases. Bioorg Med Chem. 2006;14(11):3758-65.

6. Pandey A, Dewangan D, Verma S, Mishra A, Dubey RD. Synthesis of Schiff bases of 2-amino-5-aryl-1,3,4-thiadiazole and its analgesic, antiinflammatory, anti-bacterial and antitubercular activity. Int $\mathrm{J}$ Chemtech Res. 2011;3(1):178-84.

The authors declare no conflict of interest. 
7. Chandramouli C, Shivanand MR, Nayanbhai TB, Bheemachari B, Udupi RH. Synthesis and biological screening of certain new triazole Schiff bases and their derivatives bearing substituted benzothiazole moiety. J Chem Pharm Res. 2012;4(2):1151-9.

8. Chinnasamy RP, Sundararajan R, Govindaraj S. Synthesis, characterization and analgesic activity of novel Schiff base of isatin derivatives. J Adv Pharm Tech Res. 2010;1(3):342-7.

9. Pandey A, Dewangan D, Verma S, Mishra A, Dubey RD. Synthesis of Schiff bases of 2-amino-5-aryl-1,3,4-thiadiazole and its analgesic, antiinflammatory, anti-bacterial and antitubercular activity. Int J Chemtech Res. 2011;3(1):178-84.

10. Jing Lu, Chang Li, Yun-Feng C, De-Yu Y, Cui-Rong S. The antioxidant effect of imine resveratrol analogues. Bioorg Med Chem Lett. 2012;22(17):5744-7.

11. Aboul-Fadl T, Mohammed FA, Hassan EA. Synthesis, antitubercular activity and pharmacokinetic studies of some Schiff bases derived from 1- alkylisatin and isonicotinic acid hydrazide (INH). Arch Pharmacal Res. 2003;26(10):778-84.

12. Kirandeep K, Minati B. Synthesis of Imine-Naphthol Tripodal Ligand and Study of Its Coordination Behaviour towards Fe (III), $\mathrm{Al}$ (III) and $\mathrm{Cr}$ (III) Metal Ions. Bioinorg Chem Appl. 2014. Article ID 915457, 10 pages. http://dx .do. org /10.1155/ $2014 / 915457$.

13. Mehlika DA, Ozlem A, Sinem I, Rasime D, Ahmet O, Zafer AK. Synthesis and biological evaluation of new naphthalene substituted thiosemicarbazone derivatives as potent antifungal and anticancer agents. Eur J Med Chem. 2016;108:406-14. doi: 10.1016/j.ejmech.2015.11.041.

14. Costamagna VJ, Latorre R, Alvarado A, Mena G. Coordination compounds of copper, nickel and iron with Schiff bases derived from hydroxynaphthaldehydes and salicylaldehydes. Coord Chem Rev. 1992;119:67-88.

15. Cleiton DSM, Daniel DSL, Luzia MV, Rosemeire AB, Maria DRA, Cleide MVB, et al. Schiff bases: A short review of their antimicrobial activities. J Adv Res. 2011;2(1):1-8.

16. Halli MB, Vijayalaxmi PB, Mallikarjun K, Sumathi RB. Synthesis, characterization and biological activity of complexes derived from E-N'(3,4,5-trimethoxybenzylidene) benzofuran-2-carbohydrazide and orthophenylenediamine/ 2,6-diaminopyridine. J Coord Chem. 2011;64(4):651-62.

17. Gupta VK, Jain AK, Gaurav M. Synthesis, Characterization and Pb (II) Ion Selectivity of N, N'-bis (2-hydroxy-1-naphthalene)-2,6-pyridiamine (BHNPD). Int J Electrochem Sci. 2007;2:102-12.

18. http://lilab.ecust.edu.cn/pharmmapper/index.php

19. Xiaofeng L, Sisheng O, Biao Y, Yabo L, Kai H, Jiayu G, et al. PharmMappe server: a web server for potential drug target identification using pharmacophore mapping approach. Nucleic Acids Res. 2010;38(Suppl 2):W609-14.

20. Halgren TA, Murphy RB, Friesner RA, Beard HS, Frye LL, Pollard WT, et al. Glide: A New Approach for Rapid, Accurate Docking and Scoring. 2. Enrichment Factors in Database Screening. J Med Chem. 2004;47(7):1750-9.

21. Sabat M, Vanrens C, Clark MP, Brugel TA, Maier J, Bookland RG, et al. The development of novel C-2, C-8 and N-9 trisubstituted purines as inhibitors of TNF-alpha production. Bioorg Med Chem Lett. 2006;16(16):4360-5. DOI: 10.1016/j.bmcl.2006.05.050

22. Abraham, Mark J. GROMACS: High performance molecular simulations through multi-level parallelism from laptops to supercomputers. Software $X$. 2015;1:19-25.

23. SchuEttelkopf, Alexander W, Daan MFVA. PRODRG: a tool for highthroughput crystallography of protein-ligand complexes. Acta Cryst $D$. 2004;60(8):1355-63.

24. Stewart, James JP. MOPAC: a semi empirical molecular orbital program. J Comput Aided Mol Des. 1990;4(1):1-103.

25. Essmann, Ulrich. A smooth particle mesh Ewald method. J Chem Phys. 1995;103(19):8577-93.

26. Singh RV , Chaudhary P, Chauhan S, Swami M. Microwave-assisted synthesis, characterization and biological activities of organotin (IV) complexes with some thio Schiff bases. Spectrochimica Acta Part A: Molecular and Biomolecular Spectroscopy. 2008;72(2):260-8. DOI: 10.1016/j. saa.2008.09.017

27. Alex EMD, Andrew WC, Martin JIK, Bilici A. Synthesis, Characterization and Thermal Stability of Azomethine Oligomer and Its Metal Complexes. J Appl Polym Sci. 2007;105(3):1356-65.

28. Antoine $D$, Olivier $M$, Vincent $Z$. Swiss ADME: a free web tool to evaluate pharmacokinetics, drug-likeness and medicinal chemistry friendliness of small molecules. Sci Rep. 2017;7:42717. DOI: 10.1038/srep42717

29. Ejidike IP, Ajibade PA. Ruthenium (III) Complexes of Heterocyclic Tridentate (ONN) Schiff Base: Synthesis, Characterization and its Biological Properties as an Antiradical and Antiproliferative Agent. Int J Mol Sci. 2016;17(1):60-71.

30. Ling Q, Jianguo L, Qingzhu L, Shanshan W, Gaochao LKL, Haiming S, et al. The Role of the Hydroxyl Group in Propofol-Protein Target Recognition: Insights from ONIOM Studies. J Phys Chem B. 2017;121(24):5883-96. DOI: 10.1021/acs.jpcb.7b02079.

31. Laskowski RA, Hutchinson EG, Michie AD, Wallace AC, Jones ML, Thornton JM. PDBsum: a web-based database of summaries and analyses of all PDB structures. Trends Biochem Sci. 1997;22(12):488-90.

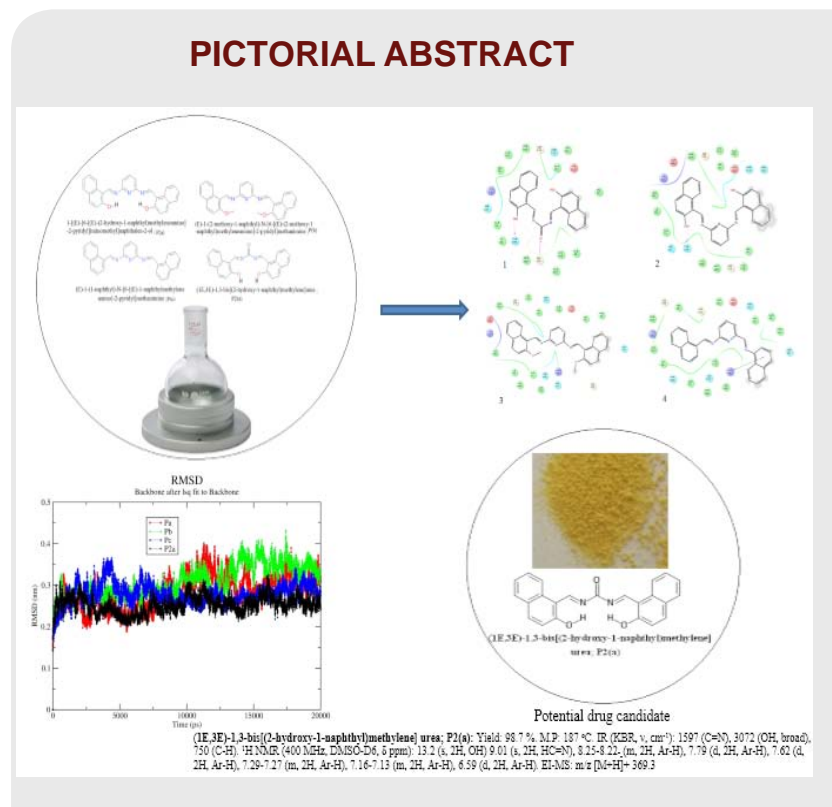

\section{SUMMARY}

- A series of Salen type (Bis-substituted) Schiff Base compounds were investigated for their Kinase inhibition proficiency. The molecular interactions and the docking results were significant enough to understand the importance of strategically placed hydroxyl functional groups in these compounds. The Schiff base P2 (a), which demonstrated better docking score exhibited good ADMET properties as well. These compounds are then synthesized and characterized for the further investigations due to their interesting binding interactions with Kinase protein. Thus, the current study presents a potential drug candidate from the Schiff Bases family. Moreover, the reverse Pharm Mapper strategy used in this paper to select the appropriate target is of greater current interest among medicinal chemists. 


\section{ABOUT AUTHORS}

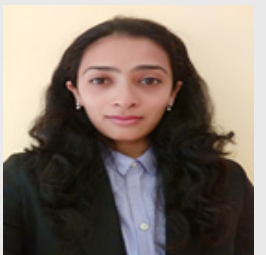

Devika Bhai Rajamma is currently perusing her Doctor of Philosophy at Bharathiar University, Tamil Nadu, India. Devika is been working with synthetic chemistry research since 2004, as she started her career as a research scientist at Syngene International Ltd, Bangalore, India. She was also associated with the Department of chemistry, The Oxford college of Science, Bangalore, India as an Assistant Professor. Her current research is mainly on Schiff bases containing fused rings and their pharmacological activities.

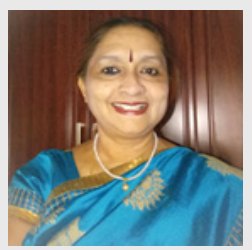

Dr.Girija Chamarahalli Ramakrishna Iyer is an Associate Professor, at Department of Chemistry, Government Science College, Bangalore, Karnataka, India. She has been engaged in teaching and research since 1985. Dr.Girija's current research interests centres on synthesis, characterisation and biological studies of heterocyclic Schiff bases and their metal complexes. She has published good number of papers in the journals of national and international repute and she is member of various science societies as well.

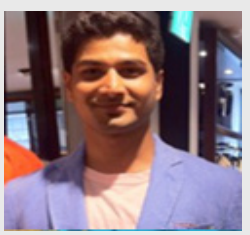

Dr. Inamul Hasan Madar is currently a visiting Scientist in the Department. of Biomedical Science and Environmental Biology at Kaohsiung Medical University (KMU), Taiwan. He is Vice president and core committee member of ISCB Regional Student Group (RSG-India). He did his BS in Biochemistry with applied Biotechnology from University of Madras and MS in Bioinformatics from Bharathidasan University. His areas of specialization are Proteomics, Computer Aided Drug Designing (CADD), Pharmacogenomics, In silico toxicology, Cancer biology.

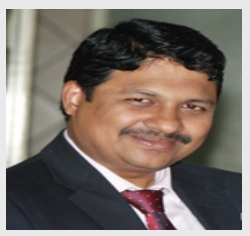

Dr. Prashantha Karunakar is an Assistant Professor at PES University Bengaluru, Karnataka, India since 2011. He worked at synchrotron facilities like DESY, Hamburg, Germany and ESRF, Grenoble, France. His research interest involves Crystallography, Bioinformatics, Computational Biology, Computational Chemistry and Molecular Docking and Dynamics Simulations.

Cite this article: Rajamma DB, Iyer GCR, Madar IH, Karunakar P. Identification of (1E, 3E)-1, 3-bis [(2-hydroxy1-naphthyl) methylene] Urea as Mutated MAP Kinase P38 Inhibitor through Reverse Pharmacophore Mapping Approach: Green Synthesis, Characterisation and in silico Docking analysis. Indian J of Pharmaceutical Education and Research. 2019;53(2):276-85. 